\title{
La noción de infinitud aplicada al movimiento: la tesis cratiliana de la total inestabilidad
}

\section{Ignacio Pajón Leyra}

Universidad Complutense de Madrid

Departamento de Filosofía III. Facultad de Filosofía.

Reception date / Fecha de recepción: 13-03-2009

Acceptation date / Fecha de aceptación: 06-05-2009

\begin{abstract}
The notion of infinity has been applied to movement: the catrilian thesis of total instability
The notion of infinity has been applied to very varied fields of study throughout the History of Greek Philosophy. Perhaps the least known among them continues to be its application to the phenomenon of motion. The question of Becoming occupied the better part of the philosophical inquiries of the $5^{\text {th }}$ and $4^{\text {th }}$ centuries BC, as they were greatly influenced by the thought of authors such as Heraclitus, Parmenides, Zenon, Democritus or Aristotle, among others. Yet perhaps the name to which we ought to relate the most extreme philosophical position based on motion is that of mysterious philosopher Cratylus, who is said to have reformulated and radicalized Heraclitus' initial theses. Cratylus would have then applied the notion of infinity to that of change, thus building the so-called "Thesis of total instability", which claims motion is not only constant, but also infinite and absolute, and therefore, the reality that is subjected to it cannot be determined.

Even though we only know about this doctrine through its mere formulation and a few not very detailed descriptions, our intention would be precisely to demonstrate that, on the basis of the testimonies transmitted to us about his thought or indirectly about his philosophical position, we can sustain that Cratylus's theory constitutes the first historical formulation of physical indeterminism.
\end{abstract}

Key words: Indeterminism, infinity, Cratylus, Becoming, Heracliteism, instability.

\section{Resumen}

A lo largo de la Historia de la Filosofía Griega, la noción de infinitud se ha aplicado sobre campos de estudio muy variados. Entre todos ellos puede que uno de los menos conocidos continúe siendo hoy en día su aplicación sobre el fenómeno del movimiento. La cuestión del devenir ocupó gran parte de las investigaciones de la filosofía de los siglos V y IV a. C., siendo central en el pensamiento de autores como Heráclito, Parménides, Zenón, Demócrito o Aristóteles, entre otros. Pero puede que el nombre con el que ha de relacionarse la más extrema de las posiciones filosóficas basadas 
en el movimiento sea el del misterioso filósofo Crátilo, a quien se atribuye la reformulación y radicalización de las tesis heraclíteas iniciales. Crátilo, de este modo, habría aplicado al cambio la noción de infinitud, construyendo así la conocida como "tesis de la total inestabilidad" según la cual el movimiento no sólo es constante, sino también infinito y absoluto, y por ello la realidad que está sujeta a él, indeterminada.

Nuestra intención será precisamente la de mostrar que, a pesar de que se trata de una doctrina que conocemos sólo por su mera formulación y por algunas descripciones no muy detalladas, en base a los testimonios que se nos han transmitido sobre su pensamiento o indirectamente sobre su posición filosófica puede sostenerse que la teoría de Crátilo constituye la primera formulación histórica del indeterminismo físico.

Palabras clave: Indeterminismo, infinitud, Crátilo, devenir, heracliteísmo, inestabilidad.

\section{I}

Uno de los principales problemas a los que se ha enfrentado la filosofía ha sido la cuestión del movimiento. Algo que la experiencia cotidiana convierte en una obviedad apenas digna de mayor atención - el hecho de que las cosas cambian, se generan, se destruyen y se mueven en el espacio - ha sido fuente de extraordinarias dificultades a la hora de darle una explicación racional coherente. No basta con señalar que percibimos el mundo como sujeto a transformaciones, sino que es necesario dar cuenta de manera satisfactoria del movimiento mismo, ya que de cómo se explique ese fenómeno, y de las implicaciones ontológicas que de esa explicación se deriven, dependerá una gran parte del modo de comprender y concebir el mundo que nos rodea.

De la importancia vital de este punto la filosofía griega fue consciente casi desde sus inicios. Las dos posiciones básicas posibles ante el tema del movimiento puede considerarse que aparecen ya en el siglo $\mathrm{V}$ a.C. La primera, la asunción del movimiento como la característica principal de la realidad, ha pasado a la historia unida al nombre de Heráclito. Y la segunda, la tesis de la inexistencia de cualquier tipo de cambio, se encuentra unida al nombre de Parménides.

En los diferentes puntos intermedios entre estas dos posturas extremas podrán situarse los filósofos posteriores que trataron de dar respuesta a la cuestión del movimiento, desde los presocráticos Empédocles, Anaxágoras y Demócrito, que tratan de salvar el movimiento de las aporías a las que la escuela eleática lo había conducido, hasta Platón y Aristóteles, que tratarán, como los anteriores aunque por distintos medios, de dar sendas explicaciones capaces de conjugar estabilidad y movimiento, eleatismo y heracliteísmo.

Con todo, quizá el nombre con el que ha de relacionarse la más extrema de las posiciones filosóficas basadas en el movimiento no sea tanto el de Heráclito como el de uno de sus seguidores, Crátilo, que reformuló y radicalizó las tesis iniciales de su predecesor. Como es 
sabido, a la famosa sentencia de Heráclito según la cual no es posible bañarse dos veces en el mismo río, ${ }^{1}$ responde Crátilo que ni siquiera una, ya que en una realidad en continuo devenir ni siquiera hay un sujeto unitario al que llamar "río".

Esta posición, que ha recibido el nombre de "tesis de la total inestabilidad", supone todo un desafío filosófico debido a las extraordinarias implicaciones que arrastra consigo. Todo fluye. Pero si es así, eso que llamamos "río" cambia constantemente mientras uno se baña en él, o incluso mientras trata de nombrarlo. ${ }^{3}$

Según Aristóteles, ${ }^{4}$ a través de esto Crátilo llegó a la conclusión de que no debía hablar. El lenguaje, en efecto, tiene sentido sólo en virtud de su capacidad para referir a los objetos. Sólo así puede predicarse algo de algo. Pero cualquier intento de predicación respecto de objetos sometidos a un devenir absoluto está abocado al fracaso. ${ }^{5}$ De ser cierta la tesis de la total inestabilidad, el objeto no es el mismo en cada instante de su cambio, por lo que ni

1. DK 12 .

2. Una forma de esquematizar las diferentes posiciones con respecto a la cuestión del movimiento sería la siguiente: 1) No hay movimiento (Escuela de Elea). 2) Hay movimiento y estabilidad; que puede subdividirse a su vez según esa presencia conjunta de estabilidad y cambio se dé 2.1) en esferas distintas (como en la teoría platónica) o 2.2) en la misma esfera (como defenderán Aristóteles, Demócrito, Anaxágoras o Empédocles, entre otros). Y, por último, 3) Sólo hay movimiento. Esta posición es la que comparten Heráclito y Crátilo, aunque, como veremos, con importantes diferencias en cuanto al modo de concebir el mundo resultante de dicha postura.

3. Igual que en la postura eleática de la "absoluta quietud" no hay "cosas" que sea posible distinguir dado que todas las cosas son una sola, inmóvil, inengendrada y eterna-, también en la interpretación cratiliana de la total inestabilidad se hace imposible la distinción en "cosas". De este modo, en gran medida también esta posición filosófica supone que todo es uno; lo unifica todo; pero no se trata del mismo tipo de uno, sino de un uno deviniente e inefable.

4. Metaf., 1010 a 12 .

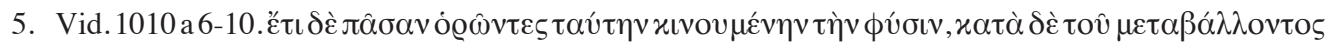

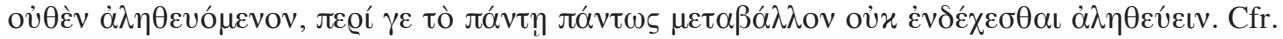

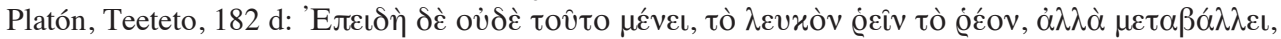

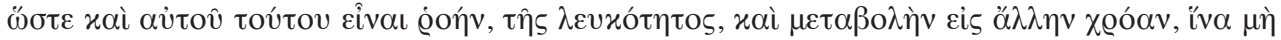

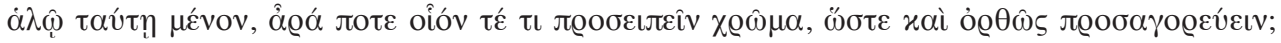
("Entonces, si ni aun esto permanece y lo que fluye no fluye blanco, sino que se muda, hasta el punto de que es fluencia de la blancura y cambio hacia otro color para evitar ser cogida como algo inmóvil, ¿será

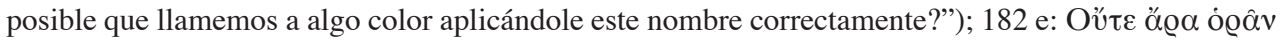

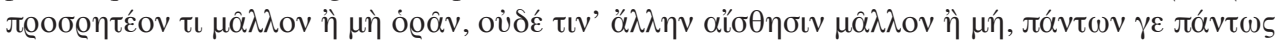

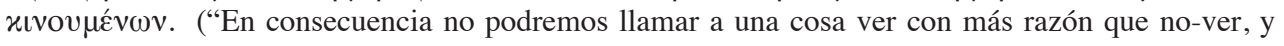
lo mismo cabe decir de las demás percepciones, puesto que todo se mueve de todas las maneras".);

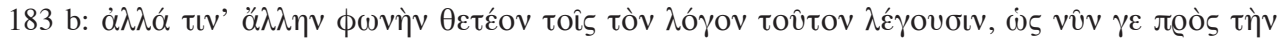

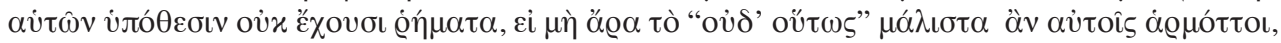

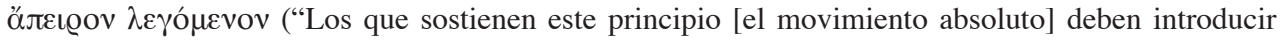
otro idioma para él, pues hasta ahora no tienen palabras aptas para sus presupuestos; debería ser algo como "ni asî", lo cual podría decir con la máxima perfección que aquí hay una indeterminación total”). 
siquiera nombrarlo es posible. $\mathrm{Y}$ al extenderse ese tipo de cambio sobre todos los objetos del mundo, el lenguaje se convierte en un absurdo inútil.

En 1010 a 13, Aristóteles comenta la alternativa por la que optó Crátilo en lo que a la comunicación se refiere: limitarse a mover el dedo. Esta noticia tan poco clara puede interpretarse como algo más que el sinsentido de un movimiento corporal como respuesta a cualquier intento de comunicación. "Mover el dedo" puede ser una forma de expresar el acto de señalar lo que se necesita, se desea o se requiere en cada instante. ${ }^{6}$ El señalar es una función de la capacidad comunicativa aceptable en un mundo sujeto al absoluto devenir. Y una función, además, que sólo requiere del movimiento de un dedo, con lo que no sólo puede corresponderse sin dificultad con el testimonio de Aristóteles, sino que además es coherente con un mundo en el que sólo hay movimiento. Lo señalado no sería concebible como un objeto, sino como un proceso. Pero el resultado comunicativo del acto de señalarlo equivaldría a la función deíctica del lenguaje.

Llama la atención que la inefabilidad del mundo derivada de la visión cratiliana del devenir resulta casi opuesta a la visión del devenir expresada por Heráclito: un devenir que se caracteriza precisamente por estar sujeto al lógos. Lo esencial del devenir heraclitiano es el lógos que lo rige, entendido como 'medida', pero también como 'razón' o incluso como 'discurso' expresable mediante el lenguaje.

Las diferencias no acaban aquí. El cambio en Heráclito es continuo. Según la interpretación platónica ${ }^{7}$ - que admitirán tanto Aristóteles como Teofrasto - la imagen del río la emplea Heráclito para ejemplificar la continuidad absoluta del devenir. Cada una de las cosas individuales se encuentra en flujo continuo, como un río. ¿Significa esto que Heráclito consideraba que todas las cosas están cambiando siempre? De ser así habría que interpretar que todo aquello que aparenta estar en completa quietud, como por ejemplo una piedra, debe estar experimentando cambios invisibles para nosotros, cambios que nuestros sentidos no son capaces de captar. Esto es lo que Aristóteles señala en Fís. 253 b 9. Pero no hay motivos suficientes para considerar que Heráclito sostuviera esta posición. Como señalan Kirk y Raven, ${ }^{8}$ algo así sería poco compatible con la confianza en la información que transmiten los sentidos de la que Heráclito hace gala. Más bien parece una posición derivada, o al menos posterior a, la crítica de los sentidos que Parménides llevó a cabo. Sólo después de que Parménides pusiera en cuestión la veracidad de la experiencia y probase que los sentidos eran engañosos y fuente de confusión sería posible una teoría que considerase a los objetos manifiestamente estables como sujetos a un devenir oculto e inadvertido.

6. De esta opinión es G. S. Kirk, (1951, p. 225-253.)

7. Platón, Crátilo, 402 a.

8. Kirk, G. S., J. E. Raven., 1957: 285. 
Un contemporáneo de Platón como Crátilo sí que pudo partir de la crítica a los sentidos parmenídea para establecer una teoría en la que el continuo devenir se extendiera de manera absoluta a todos los objetos y en todo momento.

También Meliso inició algo semejante, aunque con intenciones polémicas evidentes, en el fragmento 8, cuando advierte sobre el hecho del cambio de algunas de las cosas que parecen ser estables. ${ }^{9}$ Meliso señala que el hierro, una materia que goza de una aparente estabilidad absoluta, se gasta por la fricción de los dedos. Pero esto no significa que Meliso concibiese ese cambio de manera continua. El hierro cambiaría imperceptiblemente cuando se encuentra sometido a fricción, pero no en todo momento. Cuando no hay fricción no tiene por qué haber cambio. Para Meliso, pues, los sentidos son fuente de engaño, como para su maestro Parménides, pero además indica que todos los objetos, aun cuando parezcan estables de manera absoluta según la información sensorial de que disponemos, son en realidad susceptibles de cambio. ${ }^{10}$

La posición de Crátilo supone una radicalización de esta tesis, haciendo de todas las cosas no sólo objeto de posible cambio, sino de cambio efectivo. Así, Aristóteles resume las opiniones de Crátilo como "que todas las cosas sensibles están eternamente en devenir y que no es posible la ciencia acerca de ellas".11

Nada escapa al cambio, y no hay interrupción en él. El devenir no es ya algo regido por medida como en Heráclito, sino algo absoluto. Y es esta total inestabilidad la que impide la ciencia y el conocimiento verdadero acerca del mundo. 12

Atendiendo de nuevo al pasaje del capítulo quinto del libro IV de la Metafísica, llama la atención el hecho de que Aristóteles se refiera a la opinión de Crátilo como "la opinión más

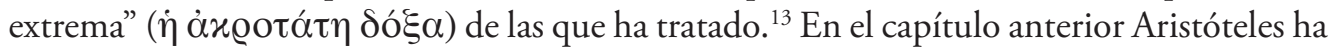
refutado a los negadores del principio de no-contradicción. En este mismo capítulo quinto ha tratado ya sobre la mayoría de las posiciones relativistas; ha mencionado a Protágoras, Anaxágoras, Demócrito, Empédocles, Parménides e incluso Homero. Y sin embargo es a Crátilo al que considera responsable de la posición más extrema. Ante este dato es inevitable preguntarse por qué. ¿Qué es lo que hace de Crátilo tan extremista? ¿Por qué Aristóteles lo considera tan radical? ¿Por negar el acceso al conocimiento verdadero? Éste es, desde luego, motivo suficiente para considerar a una teoría como bastante extremista, pero

9. Fr. 8 .

10. En el contexto de la filosofía de Meliso ha de contemplarse esta tesis como parte de los argumentos para abandonar las tesis basadas en los sentidos en favor del ser único e inmutable propio de la escuela de Elea, no como una de sus tesis efectivas; pero eso no varía el contenido de su argumentación, sino la aplicación que ha de hacerse de ella.

11. Met., 987 a 32-35.

12. Por este motivo la tesis cratiliana aparece como una de las fuentes originarias del escepticismo. (Cfr. Pauli Visova $R E, 11.2,1661,12-15$.)

13. 1010 a $10-11$. 
no es suficiente para sostener la afirmación de Aristóteles. La negación del conocimiento verdadero no puede ser la causa - o al menos no la única causa - de esa afirmación, ya que el pasaje se encuentra en el contexto de una discusión con los relativistas, y no es nada que ellos no hubieran hecho. Gorgias, por ejemplo, pero también Protágoras, niegan la posibilidad de conocer la verdad absoluta. Y además la negación del conocimiento sensible que establece Crátilo no supera en nada la de Parménides. Entonces, ¿por qué afirma Aristóteles que la tesis de Crátilo es más extrema que esas posiciones?

\section{II}

Aristóteles define el movimiento como "la actualización de lo que está en potencia en tanto que tal". ${ }^{14}$ Esta definición nos permite hacernos una idea de la conflictividad que el fenómeno del movimiento conlleva para cualquier filosofía basada en nociones como las de "sustancia" o "ser".

Antes del intento aristotélico de explicación del movimiento, cualquier filosofía que pretendiese a un tiempo dar cuenta del hecho del cambio y basarse en la estabilidad para concebir el mundo había chocado con la aparente incompatibilidad de ambas posiciones. Si se quiere esquivar la fuerza argumentativa de las aporías de Zenón, será necesario incorporar algunas hipótesis. La más evidente de ellas es la admisión de la existencia del vacío. Sin vacío, sin espacio "libre" al que pueda desplazarse lo que ocupa el espacio "lleno", no hay movimiento posible, tal y como ya percibieron, entre otros, los atomistas.

Aristóteles aplicará sobre este proceso su distinción entre la potencia y el acto. A esto dedicará la primera parte del libro III de la Física. ${ }^{15}$ Según él, todo cambio o movimiento tiene lugar necesariamente entre dos contrarios. Estos se dan en un sujeto (bypokeímenon) que es primero uno y luego otro de los polos de la contradicción, pero que permanece siendo el mismo a lo largo del proceso del cambio. De este modo, la explicación que Aristóteles ofrece no incumple el principio de no-contradicción, ya que la presencia de los contrarios en el sujeto no es simultánea. Pero tampoco incumple el postulado parmenídeo según el cual "el ser es y no puede no ser, y la nada no es, y no puede ser", ya que la segunda de ambas formas contrarias, la que está presente en el sujeto después del cambio, no procede de la nada, sino que está presente también antes del cambio en potencia. El cambio es la actualización de esa potencia ya presente en el sujeto.

14.. Fís. III, 201 a 11-2; Metaf. 1065 b 16-7. Hē tô̂ dynámei óntos entelécheia hêi toioûton. Además, vuelve a definirlo en 1065 b 33-4 como "la realización de lo potencial en tanto que potencial". († ๆov̂

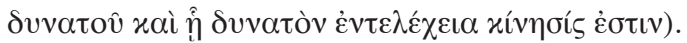

15. 200 b $1-202$ b 29 . 
En apariencia esta explicación es perfectamente satisfactoria. Pero se trata de una visión del cambio que requiere de la estabilidad. Algo tiene que permanecer en el sujeto antes y después del cambio para que pueda considerarse como el mismo sujeto. Si el cambio, como pretende Crátilo, se absolutiza, esta teoría pierde uno de los presupuestos necesarios sobre los que se apoya. Por lo tanto, la teoría de la total inestabilidad se manifiesta de partida como un enemigo irreconciliable de la visión del Estagirita.

Crátilo, en efecto, niega la autoidentidad del sustrato del cambio. Y esa negación supone el primero de los grandes enfrentamientos entre su teoría y la de Aristóteles, así como el punto de partida de varias confrontaciones más. Desde la teoría de la total inestabilidad, el principio de identidad ${ }^{16}$ pierde vigencia. En el proceso del cambio que supone, por ejemplo, para Sócrates el hecho de hacerse sabio, ya no pueden distinguirse los tres elementos que Aristóteles había señalado; no hay una forma (la ignorancia) que es contraria a otra (la sabiduría) por ser su privación, y un sujeto (el propio Sócrates) que pierde la primera porque gana la segunda (que estaba en potencia en él antes del cambio). No hay potencia, acto y actualización de la potencia en tanto que tal, porque no hay un sujeto "Sócrates" que permanezca idéntico a sí mismo antes, durante y después del cambio.

Esta negación del principio de identidad, sin embargo, no viene sola. En el caso de que el movimiento estuviese constituido de tal manera que invalidase ese principio, habría que considerar cuáles de las leyes por las que consideramos que se rige el mundo permanecen vigentes y cuáles no.

De esas leyes, la que con más frecuencia se considera como puesta en cuestión por Crátilo es el principio de no-contradicción. Negado el principio de identidad, el de nocontradicción parece imposible de sostener, ya que este último sólo se cumple plenamente en el supuesto de la autoidentidad perfecta del sujeto consigo mismo. La propia formulación del principio ("es imposible que lo mismo se dé y no se dé en lo mismo a la vez y en el mismo sentido") así lo señala.

Aristóteles incluye en el contexto de la disputa con los negadores de este principio reiteradas referencias al heracliteísmo. Si bien es cierto que la referencia directa a Crátilo no se produce hasta que comienza la refutación de los relativistas, parece probable que la teoría cratiliana fuera uno de los blancos de la argumentación aristotélica no sólo en este último contexto, sino también en el anterior.

Pero la presencia del principio de identidad en el de no-contradicción no supone que al negarse el primero se niegue también el segundo. Para negar este segundo principio es necesario afirmar que sí es posible que se den p y $\neg$ p a la vez y en el mismo sentido en el mismo sujeto. Dado que en este caso no hay tal sujeto al que llamar "mismo", el principio de no-contradicción no se niega, sino que simplemente desaparece, ya que no puede aplicarse.

16. Este principio $(\mathrm{A}=\mathrm{A})$ no aparece formulado en Aristóteles como tal principio, sino que se considera como una de las propiedades del ser. 
Desde este punto de vista, Crátilo sería un derogador del principio de no-contradicción, pero no uno de sus negadores.

A pesar de esto, tanto Aristóteles como el propio Platón parecen contar la teoría del flujo entre aquellas que afirman la posibilidad de la contradicción.

En un pasaje del Teeteto (179 d 1 y ss.) Platón pone en boca de Sócrates y Teodoro una discusión acerca de la teoría de la total inestabilidad. Y comienza precisamente afirmando que es imposible discutir con los "discípulos de Heráclito", ya que, al seguir la doctrina del flujo al pie de la letra, "se cuidan de que no haya nada estable en el discurso o en sus propias almas", ${ }^{17}$ es decir, cambian de posición continuamente para no mantener estabilidad ninguna ni siquiera en la orientación de su propia doctrina. Habrían actuado, de este modo, como si asumiesen la contradicción como una parte más de su discurso.

Aunque Platón expresa esta dificultad a través del parlamento de Teodoro, al tiempo parece desmarcarse de esta línea interpretativa en las intervenciones de Sócrates. ${ }^{18}$ Éste último, en efecto, sostiene en el diálogo que el afán por la contradicción no es más que la apariencia que se obtiene de los heraclíteos si sólo se los ha escuchado en el contexto de la disputa.

SOC.- Sin duda, Teodoro, has visto a estos hombres siempre combatiendo y no has convivido en paz con ellos, pues no eres su amigo. ${ }^{19}$

La visión de ellos que Sócrates manifiesta en el diálogo es diferente. Según él, la teoría que habrían expresado en contextos que no fueran de disputa dialéctica, por ejemplo al instruir a aquellos que toman por discípulos, habría estado muy alejada de la simple contradictoriedad. Esta noticia adquiere especial interés si tenemos en cuenta el testimonio de Diógenes Laercio según el cual Platón habría sido precisamente discípulo de Crátilo. ${ }^{20}$ Platón, pues, habría tenido acceso de primera mano a la doctrina efectiva del más acérrimo defensor de la teoría del flujo. La réplica de Teodoro a Sócrates en el diálogo, según la cual entre los heraclíteos "no hay uno que sea discípulo de otro"21, sino que surgen al azar allí donde cada uno se adhiere a la teoría del devenir, puede considerarse una referencia al propio Crátilo, que no habría sido un discípulo de Heráclito en el sentido estricto de la palabra, sino un continuador suyo. En efecto, parece probable que Heráclito no enseñara a Crátilo, sino que este último, en principio más un sofista de Atenas que un físico presocrático,

17. 180 a $9-$ b 1 .

18. Sobre la forma en que Platón expone teorías diferentes a través de los distintos interlocutores de sus diálogos véase el capítulo 9 - ¿Habla el diálogo platónico con voces diferentes? La moderna teoría del diálogo.”- del libro de Szlezák Leer a Platón. (Szlezák, 1997, p. 48-53.)

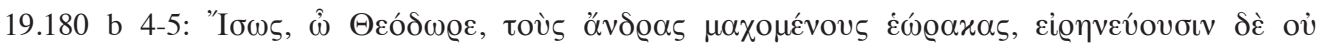

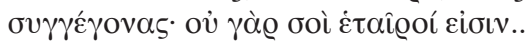

20. D. L., III, 4.

$21.180 \mathrm{c} 1$. 
habría asumido la teoría del flujo como propia por su cuenta al tener noticia de la filosofía del de Éfeso. ${ }^{22}$

Así, si Crátilo no tomó la contradicción como elemento constitutivo de su discurso, para no contradecirse se habría visto obligado a no emplear formas predicativas ni denominativas del lenguaje que pudieran comprometerle con la estabilidad de los sujetos. Sólo la pura indicación gestual le habría permitido una cierta comunicación congruente con su doctrina.

Pero el hecho de que no asumiese la contradicción como parte fundamental de su discurso no impide considerar que ese mismo discurso incluye entre sus consecuencias -fuese una consecuencia advertida o no, deseada o no, explícita o no- la derogación del principio de no-contradicción.

En su refutación de los negadores del principio de no-contradicción ${ }^{23}$ Aristóteles considera que esa negación supone también la negación de la esencia (ousía), y la afirmación de que todas las cosas suceden accidentalmente. Todo sería, pues, accidental para el negador del principio. Desde la teoría de la total inestabilidad, por su parte, también se produce la negación de la esencia. Si todo está sometido a un movimiento absoluto, esto es, si el movimiento ya no está limitado por estabilidades de ningún tipo, si el movimiento es infinito, ya no puede hablarse de entidades unitarias, autoidénticas y diferenciadas. Y además la ausencia de toda estabilidad no sólo pondría en crisis a la entidad misma, sino que obligaría a que cualquier determinación suya estuviera sometida a constante cambio. Y si todas las determinaciones no hacen otra cosa que cambiar constantemente, la distinción entre esencia y accidente desaparece. ${ }^{24}$

22. De ser así, los "partidarios de Heráclito" que florecen en Jonia según 179 d no habría que buscarlos exclusivamente en Éfeso o en sus inmediaciones. La mención de Jonia corresponde más a una filiación doctrinal que espacial. Un florecimiento de este tipo de teorías en tiempo de Sóctares y Platón ha de atribuirse a los sofistas y su entorno. Y su localización mayoritaria habría de ser, quizá, la propia Atenas, aunque fuesen llamados "jonios" o "efesios" del mismo modo en que hoy podemos incluir en el "Círculo de Viena" o la "Escuela de Frankfurt" a filósofos poco o nada relacionados con esas ciudades.

23. Véase 1007 a 21 y ss.

24. Ha de señalarse también como una de las consecuencias de este hecho la desaparición de la identidad entre la definición y lo definido. En la medida en que la definición es expresión de una esencia, no puede sobrevivir a la supresión de la diferencia entre esencia y accidentes. En un mundo regido por la total inestabilidad no habría esencia estable mediante la cual definir. Pero además, una teórica forma alternativa de definición a través de accidentes, de propios o incluso a través de la suma exhaustiva de todos los predicados de la cosa (al estilo de la definición de "hombre" como suma de todos los predicados del hombre que estipula Leibniz) se haría también imposible, ya que los predicados mismos no dejarían de cambiar. La lista exhaustiva de todos sus predicados sólo identificaría la cosa durante un instante. No habría identidad de A en un tiempo t con A en un tiempo t' (tal y como la metáfora heraclitiana del río expresa). Pero ni siquiera habría identidad dentro del mismo tiempo t (como manifiesta la versión cratiliana de esa metáfora), y no porque los predicados cambien, sino porque en un mundo regido por el devenir absoluto no hay razón para reunir esos predicados en algo como una "entidad". 
Sin este binomio puede optarse por "esencializar" todas las determinaciones o por "accidentalizarlas". Ambas opciones son sólo ligeramente diferentes. Las dos concluyen que tras cada cambio el sujeto de ese cambio no es ya el mismo. Así, en el mundo sometido al cambio se cumple la frase heraclítea según la cual "el sol es nuevo cada día" ${ }^{25}$ Eliminada la distinción esencia/accidentes, las dos opciones señaladas se convierten en mera cuestión de enfoque. Comparten las principales consecuencias ontológicas, y sólo se distinguen en el modo de interpretarlas.

En el primer caso, si se concibe que todo es esencial, cada cambio supone la aniquilación del sujeto de ese cambio y la creación de un nuevo sujeto. Esta es la alternativa que Dionisodoro plantea en el diálogo platónico Eutidemo. ${ }^{26} \mathrm{Si}$ los amigos de Clinias quieren que llegue a ser sabio, es que quieren que Clinias muera, puesto que Clinias tendría que desaparecer tal y como ahora es. La ignorancia, determinación accidental de Clinias, se esencializa, al igual que todos los demás accidentes que lo conforman. Pero si consideramos que el mundo esta sujeto a la total inestabilidad, entonces Clinias no hace otra cosa que destruirse y morir constantemente y constantemente surgir otro Clinias distinto del anterior, ya que siempre esta sujeto al cambio. El sol, pues, es nuevo cada día.

La otra alternativa, la de la "accidentalización", será la concusión predilecta para el partidario de la total inestabilidad tal y como Crátilo la plantea. No te puedes bañar ni siquiera una vez en el mismo río porque no hay una realidad a la que puedas llamar "río". El río no es el mismo en un instante y otro del baño, y tampoco lo es el hombre que se baña. Todo es accidental. No hay "río" ni "hombre". No hay nada esencial que los una y los distinga. No hay más que flujo de accidentes. Ya no sólo el sol es nuevo cada día, sino que ni siquiera hay "sol".

De este modo, la afirmación del devenir universal ha acabado con la distinción esencia/ accidentes y ha desembocado en el más absoluto accidentalismo. Cabe preguntarse ahora si la distinción aristotélica entre potencia y acto podría persistir en una teoría como la cratiliana. La respuesta es más que evidente. En un mundo sometido al absoluto cambio no puede haber nada en acto, ya que algo en acto sería por necesidad algo estático al menos en un sentido. Esto tampoco significa que pueda afirmarse que en un mundo así todo estaría en potencia. En primer lugar, en un universo en constante transformación todo sería movimiento, y el movimiento no encaja por completo ni en el acto ni en la potencia. ${ }^{27}$

En segundo lugar, tampoco puede considerarse que la teoría de la total inestabilidad implique que todo sea potencia porque de ser cierta esta teoría habría distinción entre

No hay, pues, algo unitario a lo que llamar "río". Así, la versión más extrema de la teoría de la total inestabilidad impide cualquier intento de definición. El mundo queda, literalmente, indefinido.

25. DK 6.

26. 202 c-e. Sobre este tema véase Calvo Martínez, 1988, p. 55.

27. Vid. Física III 2, 201 b 27 - 202 a 2. Véase también la nota siguiente. 
aquello que algo sí puede llegar a ser (aquello cuya potencia sí tiene) y aquello que no puede llegar a ser (aquello de cuya potencia carece). Si nada es estable, el propio movimiento no puede tener reglas estables que lo rijan y que determinen hacia dónde va a moverse. Sin esas reglas no puede decirse que inmutablemente la bellota puede llegar a ser roble, pero la castaña, la piedra o Sócrates no pueden. No habría, pues, potencias determinadas. Nada tendría más posibilidades de transformarse en A que en B. La potencia -si es que aún puede llamarse así- se hace indeterminada.

\section{III}

Cada una de las consecuencias de la teoría de la total inestabilidad que hemos visto hasta ahora parece conducir hacia el mismo punto: la indeterminación.

La supresión del principio de identidad y del de no-contradicción convierten al sujeto del movimiento en indeterminado. La eliminación de la diferencia entre esencia y accidentes, y el posterior accidentalismo hacen que las determinaciones de ese indeterminado sujeto sean también indeterminadas. Y como acabamos de ver, la desaparición de la distinción potencia/acto - y de la asunción de que algo puede tener en potencia A y no B - llevan también a la indeterminación en la propia dirección de los cambios.

Por todo ello, la realidad regida por un completo y constante devenir nos aparece como caracterizada en todos sus aspectos por una poderosa forma de indeterminismo.

La indeterminación se muestra como una de las principales consecuencias del propio movimiento. ${ }^{28}$ Pero, ¿cómo entender esa indeterminación? El indeterminismo puede darse en dos niveles diferenciados: uno meramente epistemológico y otro más bien ontológico.

Richard Bett atribuye a Pirrón de Elis y a sus seguidores lo que él llama la "tesis de la indeterminación". ${ }^{29}$ Según él, las diferentes impresiones que producen los mismos objetos observados por distintas personas o en momentos diferentes, así como los cambios en las circunstancias o perspectivas del observador y los cambios en los propios objetos habrían inducido a Pirrón a sostener que las cosas son en sí mismas indeterminadas. ${ }^{30}$

Al buscar tesis similares o emparentadas con ésta en su mismo tiempo o en periodos anteriores, Bett se fija fundamentalmente en dos pasajes de la literatura filosófica griega: la

28. Vid. Arist. Metaf. 1066 a 18-9. "La causa de que el movimiento aparezca como indeterminado es que

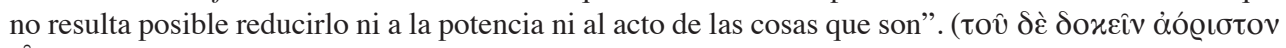

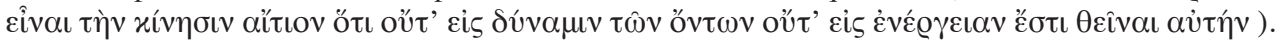
Cfr. también 1066 a 20-26.

29. También a Bett debemos la denominación de "tesis de la total inestabilidad" para la postura que entendemos que ejemplifica Crátilo (Bett, 2000, p. 123 y ss.).

30. Bett, R. 2000, p. 114 y ss. 
polémica Aristotélica con los negadores del principio de no-contradicción y el mencionado pasaje del Teeteto de Platón en que se trata sobre la tesis de la total inestabilidad.

Estas tres posiciones - tesis de la indeterminación pirroniana, negación del PNC y tesis de la total inestabilidad - se caracterizan todas ellas por concluir en el indeterminismo. Aunque hay fuertes discrepancias entre cada una de ellas, las relaciones que las vinculan también son importantes. Como acabamos de señalar, entre los fenómenos que llevan a Pirrón a concluir la indeterminación de la realidad, se encuentra el propio fenómeno del cambio. También Aristóteles considera que a la negación del PNC se puede llegar como consecuencia de una cierta interpretación del fenómeno del movimiento. ${ }^{31} \mathrm{Y}$, por supuesto, la tesis de la total inestabilidad es del movimiento de lo que parte y en lo que se basa. El hecho del movimiento es, pues, la raíz de la consideración de la realidad como indeterminada. Es la realidad misma la que se afecta por la indeterminación, y no sólo nuestro conocimiento de ella, pues no se trata sólo de que, al cambiar, nuestros sentidos no sean capaces de captar el modo en que el mundo es, sino más bien de que el hecho de estar sometido a constante cambio impide que el mundo tenga en sí mismo unas propiedades determinadas, con independencia de que podamos conocerlas o no. Nada puede ser más blanco que negro o más frío que caliente si se elimina el PNC. Y aun conservando el principio a nivel argumentativo, como trata de hacer Pirrón, la inestabilidad conlleva que el mundo se vuelva intrínsecamente indeterminista.

\section{IV}

Al margen de su indeterminismo, queda aún otro posible rasgo de la teoría de la total inestabilidad que ha de ser examinado. Tanto Platón en el Teeteto ${ }^{32}$ como Aristóteles en la Metafísica ${ }^{33}$ traen a colación la teoría del flujo en su versión más extrema en el contexto de una refutación del relativismo de Protágoras y sus seguidores. Ambas doctrinas están, efectivamente, relacionadas por el hecho de que suponen una derogación del PNC. Pero cabe preguntarse si además de esto lo están por algún otro presupuesto oculto o incluso por alguna forma de mutua implicación.

Si admitimos que la teoría cratiliana supone, en su dimensión ontológica, una suerte de indeterminismo, ¿̇tendremos que admitir también que supone relativismo en lo que a su dimensión epistemológica se refiere?

31. 1062 b 20-33; 1063 a 11-28.

$32.179 \mathrm{~d}-183 \mathrm{c}$.

33. 1010 a $10-4$. 
La tesis de Protágoras -que todas las opiniones son verdaderas- tal y como Platón la analiza, implica que "la concepción de todos y cada uno es forzosamente verdadera".${ }^{34} \mathrm{De}$ esta tesis se deduce en el texto platónico que las percepciones son todas ellas conocimiento, ya que son necesariamente verdaderas e irrefutables. Las percepciones serían, por tanto, una infalible fuente de certeza y verdad. Con objeto de probar o refutar esta última tesis aparece la referencia a la teoría de la total inestabilidad.

Si se admite que todo está en movimiento -algo que, según Platón parece dar a entender, es considerado con frecuencia una forma de relativismo- entonces ha de admitirse también que en una percepción cualquiera, por ejemplo en una percepción visual, no puede subsistir ni siquiera el ver. ${ }^{35}$ Todo tiene que cambiar en todo momento. "En consecuencia no podremos llamar a una cosa ver con más razón que no-ver". ${ }^{36}$

Esto no es más que una aplicación de la ruptura con el principio de no-contradicción que la teoría de la total inestabilidad contiene. Es, por tanto, resultado de un presupuesto (la derogación del PNC) común a relativismo y teoría cratiliana. Y sin embargo es de aquí de donde Platón extrae la diferencia radical entre la teoría del flujo y la relativista: si la percepción es conocimiento y al tiempo todo cambia, entonces habrá que decir que no es más conocimiento que no-conocimiento; que no es más verdadera que falsa. El presupuesto relativista inicialmente fijado - la infalibilidad de la percepción - ya no puede sostenerse.

En el pasaje platónico la referencia a la teoría del flujo universal parecía mostrarse como un apoyo a Protágoras. Se pretendía probar, en apariencia, que si todo se mueve, por necesidad había de admitirse el relativismo. Pero lo que Platón prueba es que si todo se mueve a todo se puede contestar de igual manera en forma afirmativa o en forma negativa. ${ }^{37}$ Nada es más afirmativo que negativo. Nada es más blanco que negro, etcétera.

¿Es esta conclusión, como se ha argumentado en ocasiones, un equivalente de la famosa fórmula escéptica "no es más" (ở $\mu \hat{\alpha} \lambda \lambda \mathrm{ov}$ )? En nuestra opinión sólo cabe responder que no, al menos si hablamos del escepticismo constituido como escuela a partir de Enesidemo. Para el escepticismo pirrónico el "no es más" es una expresión de alcance exclusivamente epistemológico. Este tipo de escéptico presupone que el modo de ser del mundo es determinado, aunque no llegue a conocerlo. Para la concepción cratiliana, en cambio, el

$34.179 \mathrm{c}$.

$35.182 \mathrm{~d}$.

$36.182 \mathrm{e}$.

37. Ciertamente, eso es algo que también podía haberse probado sin recurrir a la teoría del flujo. Sólo en base al relativismo ya se podía haber llevado a cabo, ya que el relativismo contiene también la negación del PNC. (Pues si todas las opiniones son verdaderas, tanto A como no-A son verdaderas). Sin la teoría del flujo, el argumento platónico habría podido ser muy similar a la sencilla paradoja según la cual "si todas las opiniones son verdaderas, también lo será la opinión de que esta última opinión es falsa", o, más sencillamente, "si el relativismo es verdadero entonces el relativismo es falso". 
"no es más" estaría basado en una cuestión física (el movimiento), y tendría un alcance ontológico más próximo a Pirrón que a los pirrónicos: no es que el modo de ser del mundo sea incognoscible, es que es indeterminado.

En el relativismo la indeterminación también está presente, aunque no del mismo modo. Para el relativista el modo de ser del mundo no puede determinarse absolutamente. La indeterminación procede de la subjetivización de la esfera del conocimiento. Subjetivamente todo está determinado. Cada cosa es A o es no-A para un sujeto. Pero esa propiedad A o no-A estará indeterminada en términos absolutos mientras otro sujeto pueda percibirla de manera diferente. Así, aunque la subjetivización vuelve indeterminado el mundo en términos absolutos, cada sujeto concreto lo determina de nuevo - relativamente -. En la pura teoría del flujo este juego de subjetividades está ausente. El cambio no es relativo; es absoluto, y tiene que concebirse como absoluto para que la teoría de la total inestabilidad conserve su sentido. Todo cambia absolutamente, luego no hay espacio para el relativismo.

\section{V}

Así pues, la posición cratiliana se muestra plagada de consecuencias aun cuando sólo la conozcamos por su mera formulación y una caracterización no excesivamente detallada. Esas múltiples y graves consecuencias son las que justifican que Aristóteles la considerase como la más extrema de las que trata en el libro IV de la Metafísica. Como mínimo, las consecuencias ontológicas que pueden deducirse de esta posición son las siguientes:

1.- Negación del principio de identidad

2.- Eliminación del principio de no-contradicción

3.- Accidentalismo

4.- Eliminación de la distinción potencia/acto

5.- Indeterminismo

Las cuatro primeras confluyen en la quinta de tal modo que la indeterminación ha de considerarse como la característica definitoria principal de una ontología derivada de la total inestabilidad.

En cambio, otras dos posibles consecuencias, el relativismo y el escepticismo, se muestran como incompatibles con la teoría del flujo, con la que sólo comparten un cierto rasgo común en la aporía epistemológica a la que todas ellas, de un modo o de otro y en un sentido muy lato, acaban conduciendo. 


\section{Referencias bibliográficas:}

Bett, R. (2000). Pyrrho, his Antecedents and his Legacy. Oxford University Press.

Calvo Martínez, T. (1988). "El principio de no-contradicción en Aristóteles: sus presupuestos e implicaciones de carácter ontológico", Méthexis, I, 53-71.

Kirk, G. S. (1951). "The Problem of Cratylus", The American Journal of Philology, Vol. 72, №. 3, 225-253.

Kirk, G. S., J. E. Raven. (1957). The Presocratic Philosophers. A Critical History with a Selection of Texts. Cambridge University Press, Cambridge.

Szlezák, Th. A. (1997). Leer a Platón. Madrid, Alianza. 